University of Nebraska - Lincoln

DigitalCommons@University of Nebraska - Lincoln

Challenges of Predicting the Potential Distribution of a Slowspreading Invader: A Habitat Suitability Map for an Invasive Riparian Tree

Catherine S. Jarnevich

U.S. Geological Survey, jarnevichc@usgs.gov

Lindsay V. Reynolds

Colorado State University - Fort Collins

Follow this and additional works at: https://digitalcommons.unl.edu/usgsstaffpub

Jarnevich, Catherine S. and Reynolds, Lindsay V., "Challenges of Predicting the Potential Distribution of a Slow-spreading Invader: A Habitat Suitability Map for an Invasive Riparian Tree" (2011). USGS Staff -Published Research. 734.

https://digitalcommons.unl.edu/usgsstaffpub/734

This Article is brought to you for free and open access by the US Geological Survey at DigitalCommons@University of Nebraska - Lincoln. It has been accepted for inclusion in USGS Staff -- Published Research by an authorized administrator of DigitalCommons@University of Nebraska - Lincoln. 


\title{
Challenges of predicting the potential distribution of a slow-spreading invader: a habitat suitability map for an invasive riparian tree
}

\author{
Catherine S. Jarnevich • Lindsay V. Reynolds
}

This article is a U.S. government work, and is not subject to copyright in the United States.

Received: 11 August 2009/Accepted: 16 June 2010/Published online: 2 July 2010

(C) US Government 2010

\begin{abstract}
Understanding the potential spread of invasive species is essential for land managers to prevent their establishment and restore impacted habitat. Habitat suitability modeling provides a tool for researchers and managers to understand the potential extent of invasive species spread. Our goal was to use habitat suitability modeling to map potential habitat of the riparian plant invader, Russian olive (Elaeagnus angustifolia). Russian olive has invaded riparian habitat across North America and is continuing to expand its range. We compiled 11 disparate datasets for Russian olive presence locations ( $n=1,051$ points and 139 polygons) in the western US and used Maximum entropy (Maxent) modeling to develop two habitat suitability maps for Russian olive in the western United States: one with coarse-scale water data and one with fine-scale water data. Our models were able to accurately predict current suitable Russian olive habitat (Coarse model: training $\mathrm{AUC}=0.938$, test $\mathrm{AUC}=0.907$; Fine model: training $\mathrm{AUC}=0.923$, test $\mathrm{AUC}=0.885$ ).
\end{abstract}

C. S. Jarnevich $(\bowtie)$

US Geological Survey, Fort Collins Science Center, 2150

Center Ave Bldg C, Fort Collins, CO 80526, USA

e-mail: jarnevichc@usgs.gov

L. V. Reynolds

Department of Forest, Rangeland and Watershed

Stewardship and Graduate Degree Program in Ecology,

Colorado State University, Fort Collins, CO 80523, USA
Distance to water was the most important predictor for Russian olive presence in our coarse-scale water model, but it was only the fifth most important variable in the fine-scale model, suggesting that when water bodies are considered on a fine scale, Russian olive does not necessarily rely on water. Our model predicted that Russian olive has suitable habitat further west from its current distribution, expanding into the west coast and central North America. Our methodology proves useful for identifying potential future areas of invasion. Model results may be influenced by locations of cultivated individuals and sampling bias. Further study is needed to examine the potential for Russian olive to invade beyond its current range. Habitat suitability modeling provides an essential tool for enhancing our understanding of invasive species spread.

Keywords Biological invasions .

Exotic plant species - Habitat suitability model .

Maxent · Riparian · Russian olive

\section{Introduction}

Riparian ecosystems are critical to human health, water quality, and to regional biodiversity (Naiman et al. 1993; Sabo et al. 2005). However, riparian ecosystems have been invaded by exotic species disproportionately more than other habitat types 
(Stohlgren et al. 1998; Stohlgren et al. 1999). Invasive species in riparian areas can decrease habitat quality for native fauna, out-compete native plants and threaten the biotic and hydrologic integrity of these river systems (Hood and Naiman 2000; Richardson et al. 2007). The importance of riparian ecosystems on a global scale has motivated researchers and land managers to study processes of riparian plant invasion and develop corresponding management strategies (HR2720 2006; Shafroth et al. 2008).

One of the most dominant woody plant invaders along rivers in western North America is Russian olive (Elaeagnus angustifolia L.; Friedman et al. 2005). Russian olive is native to southern Europe and Asia and was introduced to North America around 1900 as an ornamental plant and for windbreaks (Katz and Shafroth 2003). It can tolerate greater soil drought than native riparian species and has the advantage of being a nitrogen-fixing plant (DeCant 2008; Katz and Shafroth 2003). Russian olive produces large seeds that are animal dispersed and viable for up to 3 years (Katz and Shafroth 2003). In contrast, the common native woody riparian plants cottonwood (Populus species) and willow (Salix species), produce airborne seeds which are only viable for four to six weeks during the summer growing season (Cooper et al. 1999). Cottonwood and willow require flooded, high-light habitat for seed germination whereas Russian olive can germinate in shadier and drier environments than native woody riparian plants (Reynolds and Cooper 2010; Shafroth et al. 1995). Although Russian olive occurs frequently along western rivers, it has not yet invaded all potentially suitable habitat (Friedman et al. 2005; Reynolds and Cooper 2010). In addition, a comprehensive inventory of its distribution does not currently exist. Understanding the potential spread of any invasive species such as Russian olive is essential for land managers to prevent its establishment, control its spread and restore impacted riparian habitat.

Habitat suitability models provide a tool for researchers and managers to understand the potential extent of invasive species spread. Habitat suitability models can fill data gaps in survey records and can highlight priority locations for future surveying and monitoring (Jarnevich et al. 2006). Maximum entropy modeling (Maxent) is one of a suite of habitat suitability modeling techniques requiring only presence locations (Phillips et al. 2006). Maxent is a machine learning method that compares presence locations to environmental variables at those locations and then across the study area using principles of maximum entropy to generate predictions of suitable habitat in un-sampled regions. It is userfriendly, produces robust metrics to evaluate model fit and has proven effective in predicting habitatspecific species such as saltcedar (Tamarix sp.) at small spatial extents (Evangelista et al. 2008). Presence only methods such as Maxent are appropriate for modeling species with unstable distributions such as invasive species because true absence data can be difficult to obtain. If a species is absent at a location, it could either be because it has not yet invaded or because the location is unsuitable, and these two options are often indistinguishable for invasive species.

We compiled data sets of Russian olive presence locations across the western US from land managers, government agencies and researchers to map potential habitat of Russian olive in the western US. We used Maxent to develop estimates of potential Russian olive habitat as rapid assessment of range expansion for invading species is critical to stopping their spread. Because Russian olive has been shown to tolerate drier conditions than native riparian species, we built two models: one with a fine-scale resolution water body variable and one with a coarsescale resolution water body variable, to test the importance of water bodies for this riparian species. Our goals were to inform management of Russian olive invasion, provide a methodology to predict the spread of other slow-spreading exotic species invasions, and to highlight important issues in developing models for invasive species that are used ornamentally.

\section{Methods}

We compiled 11 disparate datasets for Russian olive presence locations in the western US. The majority of datasets were from data holders who shared their datasets on the National Institute of Invasive Species Science (NIISS) website (http://www.niiss.org, Table 1). To augment these data, we contacted state weed coordinators and other land managers to obtain weed mapping data, and searched the internet to 
Table 1 Datasets gathered with Russian olive presence locations
Data from www.niiss.org were downloaded July 2 , 2008

\begin{tabular}{lll}
\hline Source organization & Sample size & On \\
& & NIISS.org \\
\hline Colorado (CO)Dept. of Transportation & 55 polygons & Yes \\
CO State Parks mapping data (Billerbeck 2003) & 124 points, & \\
& 84 polygons & Yes \\
Fingerprinting biodiversity (CSU and USGS field data) & 69 points & Yes \\
Friedman et al. (2005) data & 144 points & Yes \\
Grand Staircase Escalante National Monument & 52 points & Yes \\
(Evangelista et al. 2008) & & \\
National Park Service GIS data (NPS 2003) & 3 points & Yes \\
National Wildlife Refuge Project & 4 points & Yes \\
NIISS Citizen Science Website Projects & 16 points & Yes \\
UC Davis plot data (Quinn and Thorne 2007) & 11 points & No \\
Royal Gorge (Vieira 2003) & 14 points & No \\
Southwest Exotic Plant Mapping Program (Thomas and & 366 points & Yes \\
Guertin 2007) & & \\
Utah BLM office (2006) & 248 points & No \\
Total number of presence locations & 1,051 points and 139 & \\
& polygons & \\
\hline
\end{tabular}

locate Geographic Information System (GIS) mapping layers. Most data are currently available at http://www.niiss.org, including all freely available data, or where permission was granted from the data providers.

We generated Maximum Entropy (Maxent; v 3.2.19; available from http://www.cs.princeton.edu/ $\sim$ schapire/maxent/) models of habitat suitability for Russian olive using the available presence location data from all point and polygon datasets (Phillips et al. 2006). Because polygons of Russian olive stands were relatively small compared to the spatial resolution of GIS predictor layers (i.e., $1-\mathrm{km}^{2}$ ), we used the centroid of the polygons, making sure they fell within the polygon boundaries. This manipulation resulted in 4,698 points, some of which occurred in the same pixel. We reduced this number to 961 unique $1-\mathrm{km}^{2}$ cells with Russian olive present. We ran 25 iterations of each model, withholding a different $30 \%$ of the data points each time for model cross-validation.

We obtained 37 climatic, topographic, and geologic variables for predictors in modeling. These included 19 bioclimatic variables that capture annual and seasonal trends in local climate derived from monthly temperature and precipitation from DAYMET using an ArcGIS script available from WorldClim (DAYMET 2006; Hijmans 2006). Topographic variables were elevation, slope and aspect. We also used a geology layer detailing bedrock geology. We reduced these predictors by removing any highly correlated variables $(r>+0.8$ or $r<-0.8)$, resulting in 22 climate, topography, and geology predictor variables. To address the question of how sensitive Russian olive distribution is to water bodies, we used two different measures of "distance to water." First, we built a model with all 22 climate, topography and geology variables and a distance to water variable of coarse-scale resolution derived from the National Atlas of the United States Streams and Waterbodies layer $(1: 2,000,000$ scale, hereafter "coarse-scale water model"). Second, we built a model with all 22 climate, topography and geology variables and a distance to water variable of fine-scale resolution derived from the National Hydrography Dataset Plus (1:100,000 scale, hereafter "fine-scale water model”). Maxent is a statistical technique and therefore we cannot infer causal relationships between the predictor variables and habitat suitability, but we chose variables that relate to the physiology of Russian olive (Table 2).

Maxent is sensitive to sampling biases such as those in the clustered, disparate data set we compiled (Phillips 2008). To alleviate this problem we limited the spatial extent from which Maxent could select background points to counties where we had Russian 


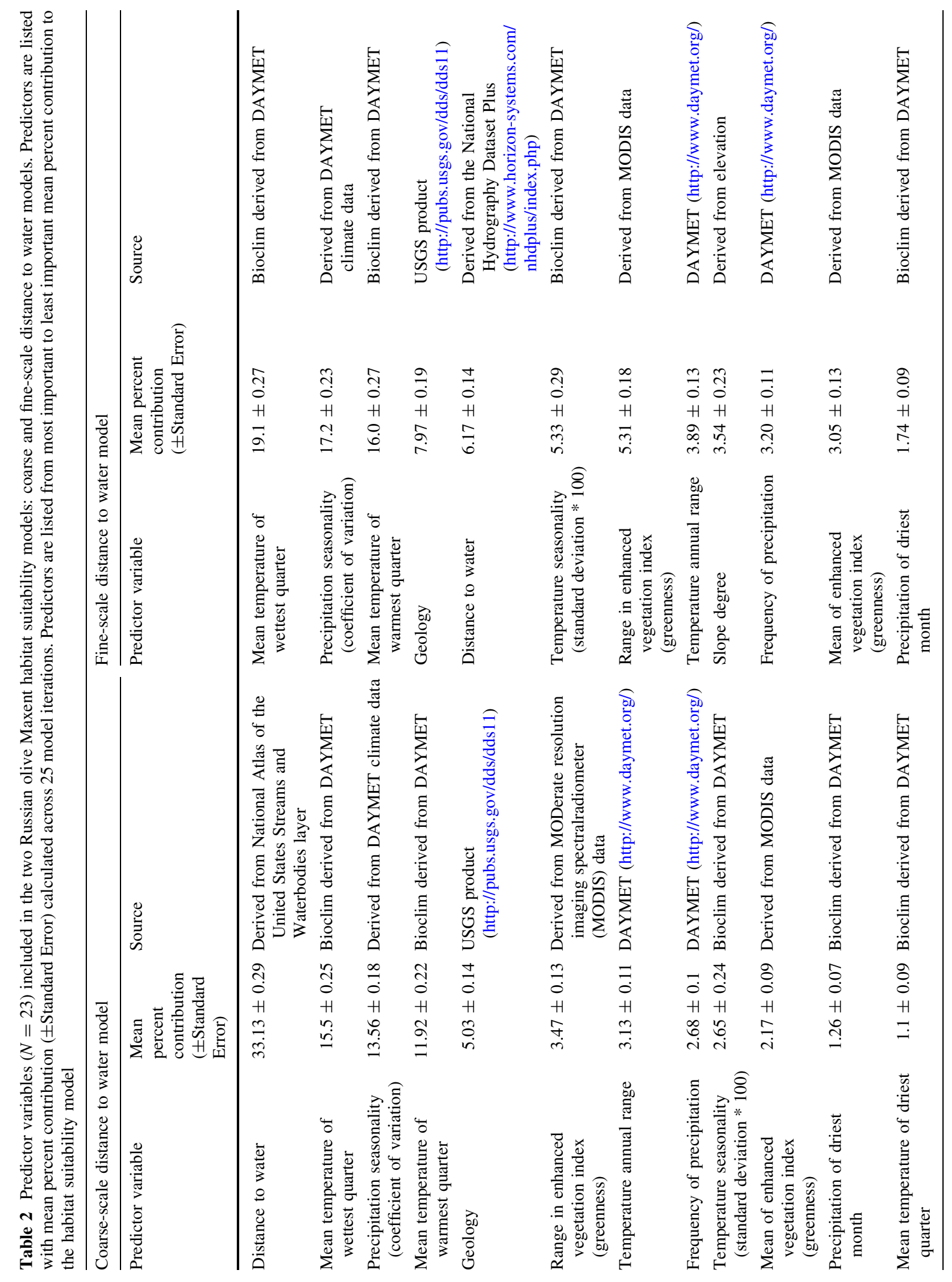




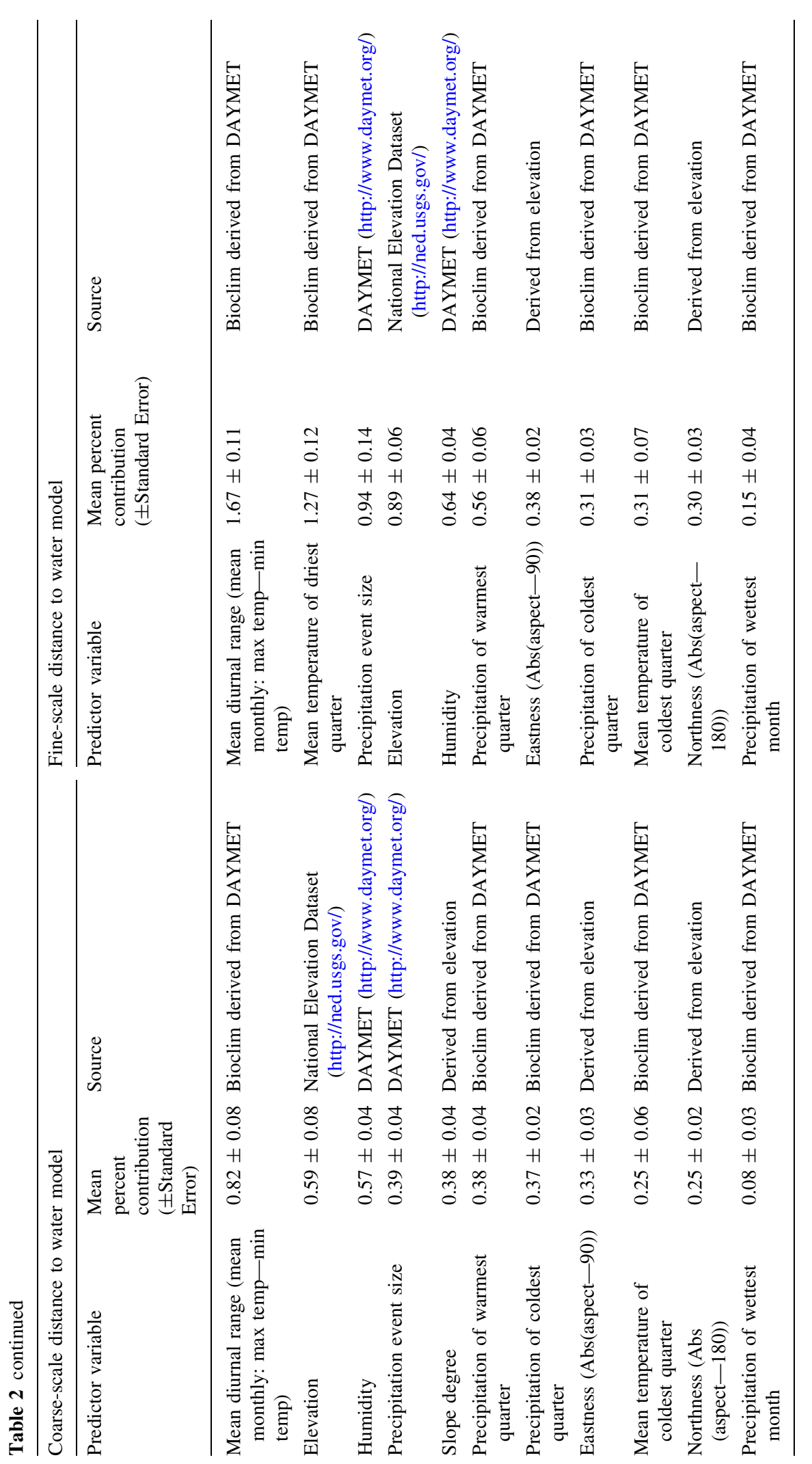


olive locations. We then projected this model to the entire Western US. For each of the two different water models (coarse and fine-scale water models), we produced three maps for the western US averaged across 25 model runs: a map of predicted suitable habitat, a map of standard deviation between predictions from the 25 runs, and a map showing average clamping across the 25 runs. Clamping indicates where a model is projected to new areas and those new areas have environmental conditions outside the range of the locations used in training the model.

For both coarse and fine-scale water models we also generated a binary map of predicted suitable and unsuitable habitat using a 10 percentile training presence threshold calculated by Maxent. This suitability threshold selects the value above which $90 \%$ of the training locations are correctly classified. It provides a more conservative model than the minimum training presence threshold which correctly predicts every training location and may lead to overprediction. Choice of a threshold can have a great effect on maps (Freeman and Moisen 2008), and we choose a subjective threshold based on a desired accuracy rather than using more complex methods requiring both presence and absence data (for example, see Jimenez-Valverde and Lobo 2007; Liu et al. 2005). This method matches the Freeman and Moisen (2008) required specificity threshold criteria. We placed more weight on not missing habitat; if an alternative management objective is required, a different classification should be used.

Maxent calculates an area under the receiver operating characteristic (ROC) curve (AUC) to evaluate model performance. The AUC is a threshold-independent measure of model performance that determines how well a model discriminates between presence locations and, with Maxent, other locations in the area of interest. AUC values can range between 0.5 and 1.0 , with 0.5 indicating no discrimination ability; values below 0.7 are low, values between 0.7 and 0.9 are useful in some cases, and values $>0.9$ indicate high discrimination (Swets 1988). We calculated an AUC for the training dataset and an AUC for the test data we withheld for both models. We also calculated the predicted to expected (P/E) ratio for both models where a graph of predicted versus expected for a good model should show a monotonically increasing curve (Bradley et al. 2009; Hirzel et al. 2006). We did not calculate other common metrics such as kappa and specificity as we did not have the required absence location data set to use.

\section{Results}

A regional database for the southwest, Southwest Exotic Mapping Program (SWEMP), provided the most presence location data, with emphasis in Arizona and New Mexico (2007). Likewise, the state of Utah had previously compiled weed mapping data (2006). The state of Colorado had already been heavily targeted by past research projects and included hundreds of presence locations (Crosier 2004). Data for Montana, Wyoming, West Coast states, and the central plains states were generally sparser than for the other states (Fig. 1).

For each model iteration, we had 603 training locations to develop the model and a different 258 test locations for cross-validation. For the coarsescale water model, the average training AUC and test AUC across the 25 iterations were 0.938 ( $\mathrm{SD}=$ $0.002)$ and $0.907(\mathrm{SD}=0.009)$, respectively. The $\mathrm{p} / \mathrm{e}$ ratio was better than random as values were always greater than the 1:1 line for the predicted versus expected graph. A graph of the ratio versus habitat

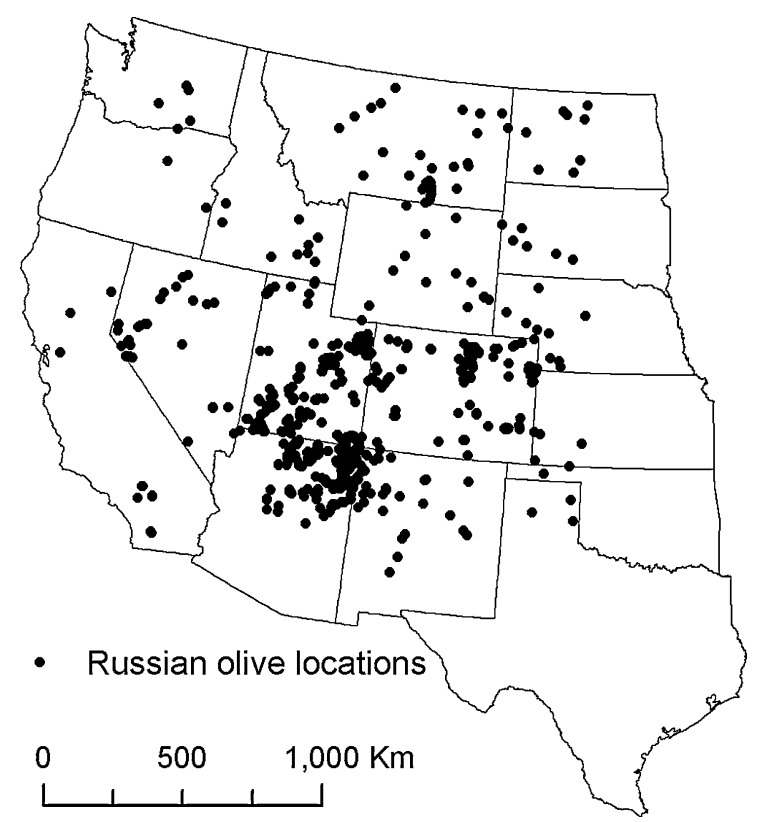

Fig. 1 Recorded locations of Russian olive from compiled datasets listed in Table 1 (North America Albers Equal Area Conic projection) 
suitability increased with increasing suitability. The value at our threshold of 0.9 was 4.44 . Distance to water was the most important predictor, with an average relative contribution to the model of $33.1 \%$ (Table 2). Increased distance from water resulted in an exponential decrease in habitat suitability. Three other variables had greater than $10 \%$ importance in the model: mean temperature of the wettest quarter of the year (15.5\% contribution), precipitation seasonality ( $13.6 \%$ contribution), and mean temperature of the warmest quarter (11.9\% contribution). Suitability was high with extreme temperatures (both low and high) during the wettest quarter and with extreme (low and high) levels of precipitation seasonality. Suitability was lowest with intermediate-temperatures during the wettest quarter and intermediate-levels of precipitation seasonality. Suitability had a positive relationship with mean temperature of the warmest quarter, increasing with increasing temperatures.

For the fine-scale water model, the average training AUC and test AUC across the 25 iterations were $0.923(\mathrm{SD}=0.003)$ and $0.885(\mathrm{SD}=0.01)$, respectively. The p/e ratio was again better than random, and a graph of the ratio versus habitat suitability increased with increasing suitability. The value at our threshold of 0.9 was 3.78. Mean temperature of the wettest quarter of the year was the most important predictor for this model (19.1\% contribution), followed by precipitation seasonality $(17.2 \%$ contribution), and mean temperature of the warmest quarter (16.0\% contribution, Table 2). The relationships between Russian olive habitat suitability and variables with greater than $10 \%$ contribution were the same as for the coarse-scale water model, refer to the preceding paragraph for relationships between habitat suitability and the variables mean temperature during the wettest quarter, precipitation seasonality, and mean temperature during the warmest quarter. Distance to water ranked fifth in importance, with an average relative contribution to the model of $6.2 \%$ (Table 2). Increased distance from water resulted in an exponential decrease in habitat suitability.

Suitable Russian olive habitat in the western US closely follows the paths of water bodies for the coarse-scale water model and follows a similar distribution with a wider buffer around dense water body areas for the fine-scale water model (Fig. 2a, d). Areas of concentrated suitable habitat include the
Colorado Plateau region, the front range of the Rocky Mountains, the central valley region of California, and the fine-scale water model also included high densities in northern Texas, Oklahoma and eastern Kansas. Of those concentrated locations, those in California, northern Texas, Oklahoma and eastern Kansas also have high standard deviation between the model runs (Fig. 2b, e) and a high degree of clamping (Fig. 2c, f). Predictions in these areas have a high degree of uncertainty. Habitat suitability patterns become clearer when habitat suitability is defined according to the $90 \%$ suitability threshold (Fig. 3).

\section{Discussion}

Our models of Russian olive habitat suitability predicted existing presence points well, with the coarse-scale water model performing slightly better than the fine-scale water model (Coarse model: training $\mathrm{AUC}=0.938$, test $\mathrm{AUC}=0.907$; Fine model: training $\mathrm{AUC}=0.923$, test $\mathrm{AUC}=0.885$ ). Our habitat suitability models shows that some riparian areas along the western coast of North America are threatened by Russian olive, although it has not yet invaded these areas-at least not according to the presence data we were able to gather. However, these locations also had high clamping and standard deviation in model runs, indicating some uncertainty in the predictions. Targeted sampling in these locations may improve further model iterations. Similarly, the models show that the central part of North America is vulnerable to Russian olive invasion, although there is currently little data for Russian olive presence in this region.

Surprisingly, our models show no southern limit to Russian olive invasion in the western US except in extreme southern Texas and the southern California and Arizona border. Other research has shown that Russian olive occurrence is limited by temperature in southern California, Arizona and New Mexico (Friedman et al. 2005). Coarse-scale distribution maps, such as those available from the USDA plants database, include state and county level Russian olive presence in Midwestern states and the southern US (USDA 2009). Our field data used to create the model do show a clear Southern boundary, but we cannot be certain if this is a sampling artifact or an environmental limitation to Russian olive distribution. 
Fig. 2 Model results for Russian olive coarseresolution water data model (a-c) and the fine-scale water model (d-f) including a, $\mathbf{d}$ habitat suitability using all data points, b, e standard deviation between the 25 model iterations using different subsets of point data indicating sensitivity of model to presence locations, and $\mathbf{c}, \mathbf{f}$ locations where clamping occurred highlighting locations with environmental conditions outside the range of the locations used to generate the model (North America Albers Equal Area Conic projection)

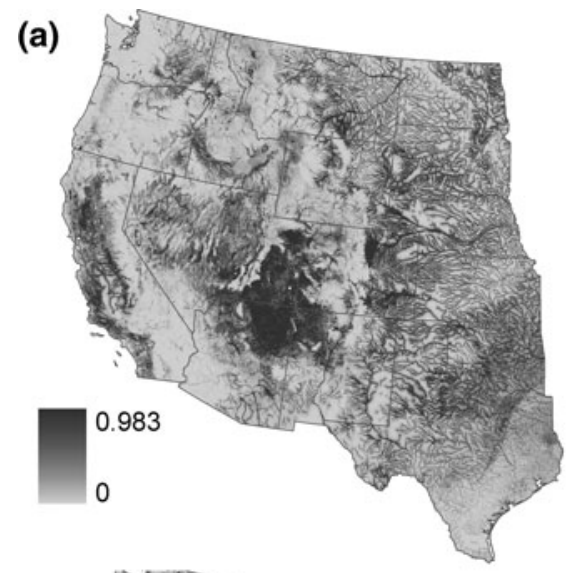

(d)
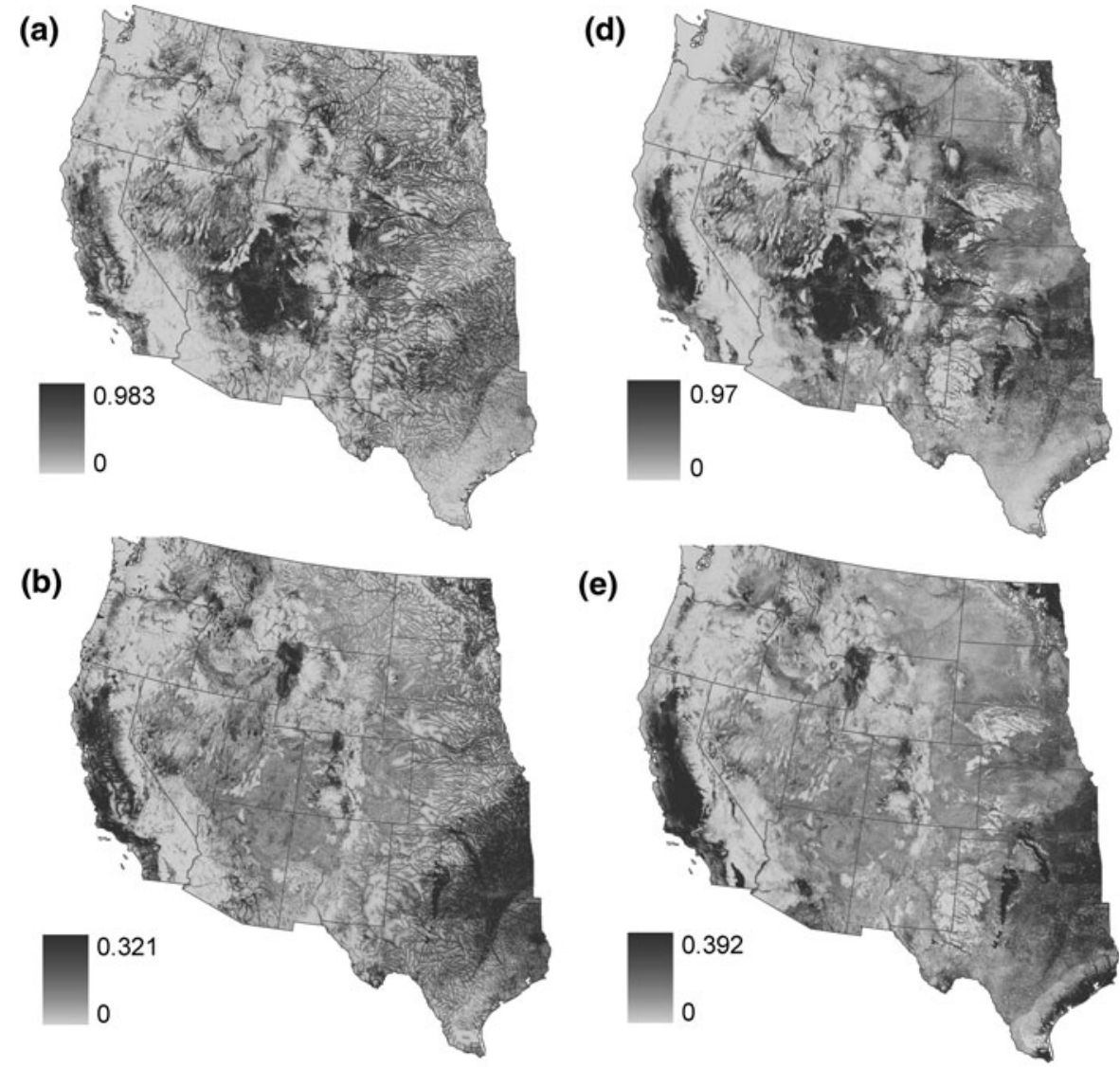

(e)
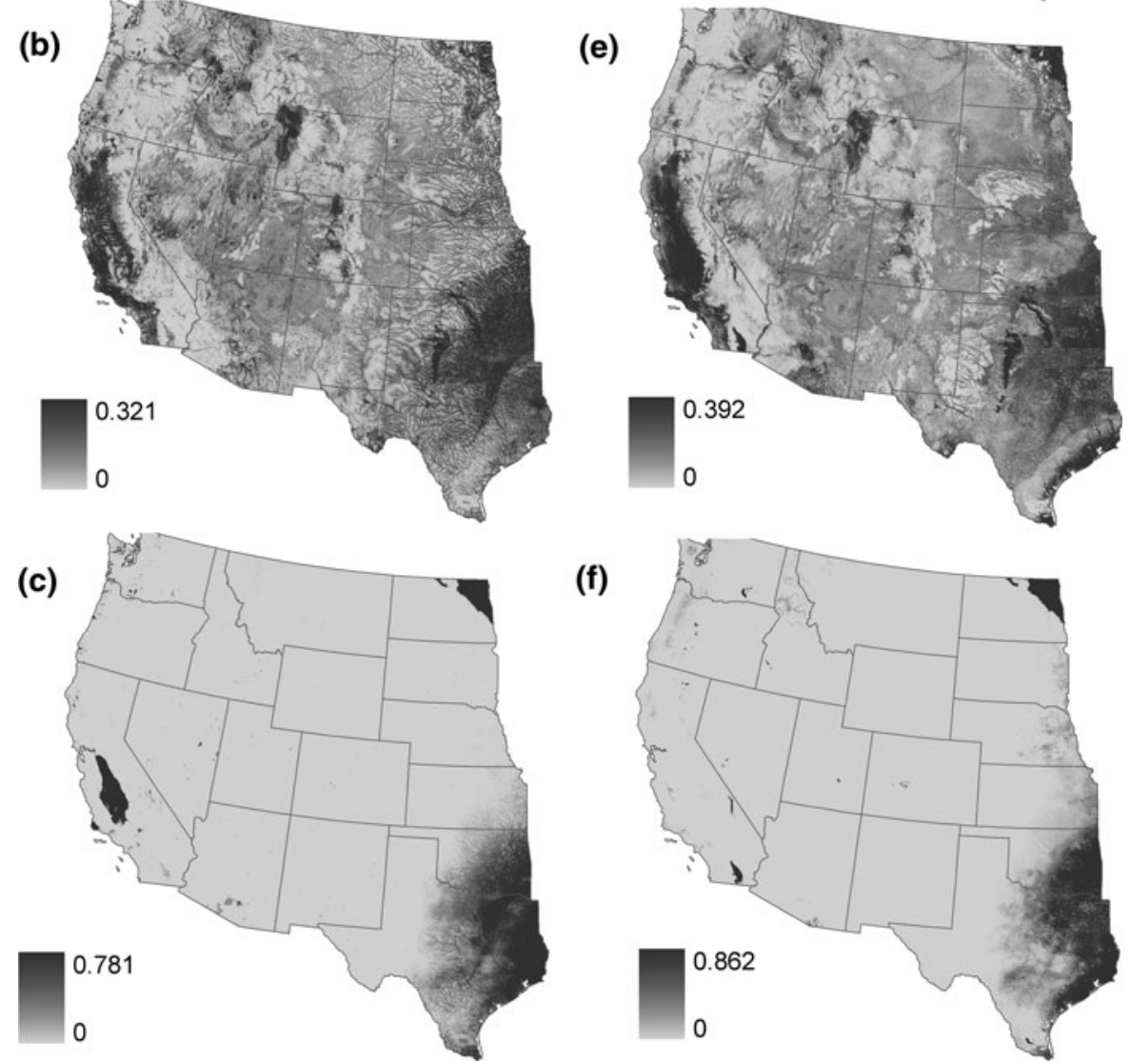

(f)

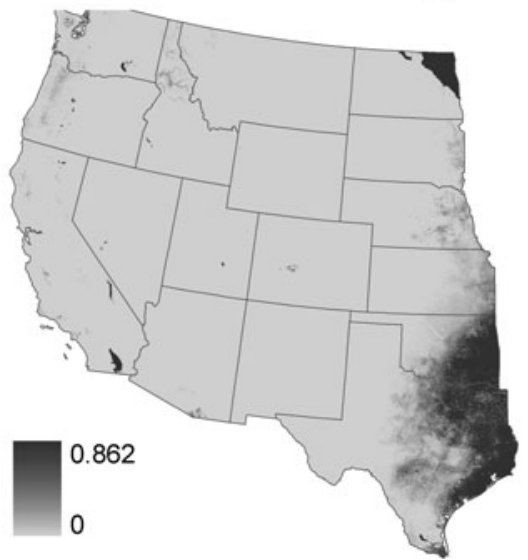

Distance to water was the most important predictor for Russian olive habitat suitability in our coarse-scale water model, however, it was only the fifth most important variable in the fine-scale model. This difference is surprising for a species that is considered to be riparian. We expected Russian olive to closely follow water bodies in both models. These results indicate that when water bodies are considered on a fine scale, including small water bodies, Russian olive is more sensitive to other environmental conditions than distance to water. This finding supports other research that has found Russian olive to be less dependent on shallow riparian water tables than other obligate riparian species (Katz et al. 2005; Lesica and Miles 1999; Reynolds and Cooper 2010). Moreover, the fact that 

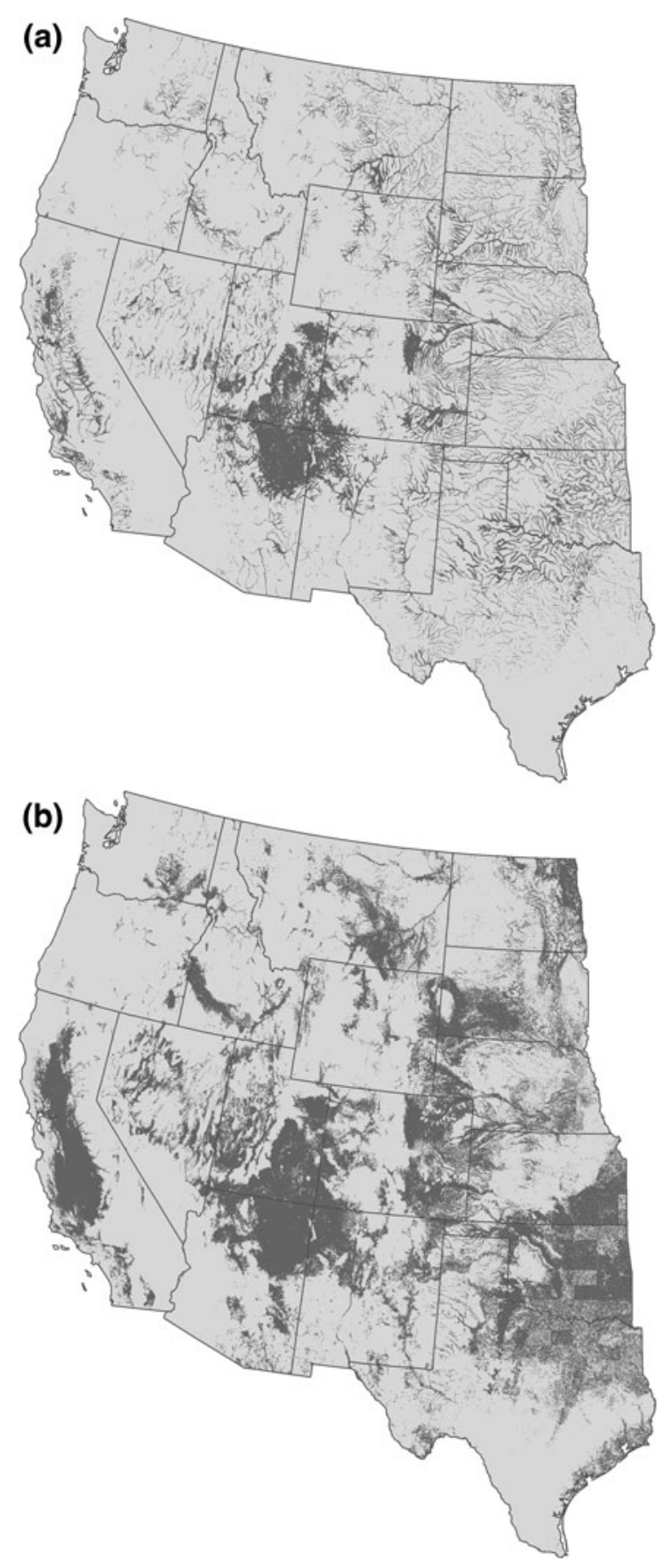

Fig. 3 Map of suitable and unsuitable habitat for Russian olive using the 90 percentile training presence threshold of 0.363 for a coarse-resolution water data model and $\mathbf{b}$ fine-resolution water data model (North America Albers Equal Area Conic projection)

the coarse-scale model is a better fit according to AUC and p/e measures suggests that a good framework for understanding potential Russian olive

distribution should consider a wide buffer around major water bodies.

For both coarse and fine-scale water models, results for important (greater than 10\% importance) variables indicate suitable Russian olive habitat includes the hottest, driest regions and regions with the most variable precipitation regimes in western North America. Habitat suitability had a positive relationship with mean temperature of the warmest quarter, increasing with increasing temperatures. Russian olive habitat suitability was also positively related to extreme temperatures during the wettest quarter. These results correspond to the climate of the western US at high elevations and northern latitudes where the wettest quarter occurs during winter months with extremely low temperatures and at low elevations and southern latitudes where the wettest quarter is during the summer monsoon season with extremely high temperatures (Gochis et al. 2006). Russian olive is well-suited for the arid regions of North America because of its original adaptation to temperate, arid regions of Eurasia. It may do well in these locations because of its broad tolerances to winter temperatures, extreme summer temperatures and drought (Katz and Shafroth 2003).

More research is needed into how models perform with biased datasets like those generally available for invasive species across large spatial extents. Most of our data were compiled from disparate efforts, each with unique sampling goals and strategies. We cannot differentiate between poorly sampled areas, areas that could be invaded but have not been yet, and true absence areas. Sampling incompleteness and uncertainty exacerbate the issues related to assessing sampling bias. Phillips et al. (2009) recently examined the issues of sample selection bias with Maxent, but our data set was not amenable to their solution of using other species' locations collected in the same dataset as background locations. We attempted to alleviate bias by limiting background locations to counties where we had sample points.

Also, some presence locations for Russian olive may be places where it has been planted but is not necessarily naturalized. Russian olive was originally planted in the US for wind breaks and as an ornamental plant. Although considered a noxious weed in most western states, it can still be purchased at nurseries in some states: an internet search revealed that Russian olive can be purchased in 
places where it could also be invasive, such as Nebraska. In fact, horticulture is the number one pathway of introduction for woody invasive species in the US (Richard and White 2001). Ornamental plants that become naturalized and invasive are a challenging issue for scientists and land managers. There is a lag time between recognition of the plant as a problematic weed and when people stop planting it. This makes it hard for scientists to determine potential habitat in its introduced range because planted areas may not reflect suitable habitat (Strayer et al. 2006; Wilson et al. 2007).

Our model was only based on climatic and other abiotic data. There may be other factors limiting the extent of Russian olive including biotic interactions such as competition for resources, geographic barriers to dispersal, and other environmental parameters such as soil composition for which we did not have data available. Including these factors may improve the fit of distribution models (Araujo and Luoto 2007; Heikkinen et al. 2006).

As with all models, there are associated caveats; however, it is a useful tool for identifying potential Russian olive invasion areas. Species distribution models can be used to inform field-based studies testing the importance of abiotic variables and to inform field site selection on the landscape. Further study is needed to examine the potential for Russian olive to invade beyond its current range in North America, especially in the context of global climate change. We used current climate conditions to build our model, but it is increasingly imperative to understand how species will respond under potential future climate conditions (Bradley et al. 2010). Russian olive could be experimentally planted at the edges of its range to understand its distribution limits and possible shifts under climate change scenarios. It takes several years for Russian olive trees to develop from the seedling stage to reproductive maturity, so it would be possible to sow Russian olive seeds and then remove the trees before they reproduce (Katz and Shafroth 2003). This would be a useful way to test habitat suitability without spreading the invasive plant. If scientists can determine the boundaries of Russian olive invasion in the western US and how those boundaries may change over time, managers can direct their efforts accordingly.

To respond effectively to the threats of invasive species on natural ecosystems, scientists and managers need tools with which to predict invasive species spread. Predicting the spread of a slow invader before it has filled potential habitat types in its introduced range is difficult. To combat these challenges, we must use all available tools to predict invasive species potential spread: detailed knowledge of the species' biology and ecology, key environmental predictors in its historic ranges, and habitat suitability models. Models must be used carefully and in concert with other information to be most effective.

Acknowledgments We would like to thank the many people who donated datasets to our research efforts especially the Southwest Exotic Plant Mapping Program, the Utah BLM office, the Colorado Department of Transportation, Pat Shafroth and Jonathan Freidman. We thank the National Park Service, Colorado State University and the US Geological Survey Fort Collins Science Center for logistical support. We thank Jonathan Friedman and Tom Stohlgren for providing comments on an earlier version of our manuscript. Any use of trade, product, or firm names is for descriptive purposes only and does not imply endorsement by the U.S. Government. Two anonymous peer reviewers provided additional comments. To all we are grateful.

\section{References}

Araujo MB, Luoto M (2007) The importance of biotic interactions for modelling species distributions under climate change. Glob Ecol Biogeogr 16:743-753

Billerbeck R (2003) Colorado state parks weed data. Colorado State Parks

Bradley BA, Oppenheimer M and Wilcove DS (2009) Climate change and plant invasions: restoration opportunities ahead? Global Change Biology

Bradley BA, Blumenthal DM, Wilcove DS and Ziska LH (2010) Predicting plant invasions in an era of global change. Tree (in press)

Cooper DJ, Merritt DM, Andersen DC, Chimner RA (1999) Factors controlling the establishment of Fremont cottonwood seedlings on the upper Green River, USA. Reg Rivers Res Manage 15:419-440

Crosier CS (2004) Synergistic methods to generate predictive models at large spatial extents and fine resolution, Graduate Degree Program in Ecology. Colorado State University, Fort Collins, p 119

DAYMET (2006) Climatological summaries for the conterminous United States, 1980-1997. Daily surface weather and climatological summaries (DAYMET; http://www. daymet.org)

DeCant JP (2008) Russian Olive, Elaeagnus Angustifolia, alters patterns in soil nitrogen pools along The Rio Grande River, New Mexico, USA. Wetlands 28:896-904

Evangelista PH, Kumar S, Stohlgren TJ, Jarnevich CS, Crall AW, Norman JB, Barnett DT (2008) Modelling 
invasion for a habitat generalist and a specialist plant species. Divers Distrib 14:808-817

Freeman EA, Moisen GG (2008) A comparison of the performance of threshold criteria for binary classification in terms of predicted prevalence and kappa. Ecol Modell 217:48-58

Friedman JM, Auble GT, Shafroth PB, Scott ML, Merigliano MF, Preehling MD, Griffin EK (2005) Dominance of non-native riparian trees in western USA. Biol Invasions 7:747-751

Gochis DJ, Brito-Castillo L, Shuttleworth WJ (2006) Hydroclimatology of the North American Monsoon region in northwest Mexico. J Hydrol 316:53-70

Heikkinen RK, Luoto M, Araujo MB, Thuiller W, Sykes MT (2006) Methods and uncertainties in bioclimatic envelope modelling under climate change. Prog Phys Geogr 30:751-777

Hijmans RJ (2006) MkBCvars.AML version 2.3. http://world clim.org/bioclim.htm

Hirzel AH, Le Lay G, Helfer V, Randin C, Guisan A (2006) Evaluating the ability of habitat suitability models to predict species presences. Ecol Modell 199:142-152

Hood WG, Naiman RJ (2000) Vulnerability of riparian zones to invasion by exotic vascular plants. Plant Ecol 148: $105-114$

HR2720 (2006) Salt Cedar and Russian Olive Control Demonstration Act. United States Congress

Jarnevich CS, Stohlgren TJ, Barnett D, Kartesz J (2006) Filling in the gaps: modelling native species richness and invasions using spatially incomplete data. Divers Distrib 12:511-520

Jimenez-Valverde A, Lobo JM (2007) Threshold criteria for conversion of probability of species presence to either-or presence-absence. Acta Oecologica Int J Ecol 31:361-369

Katz GL, Shafroth PB (2003) Biology, ecology and management of Elaeagnus angustifolia L. (Russian olive) in western North America. Wetlands 23:763-777

Katz GL, Friedman JM, Beatty SW (2005) Delayed effects of flood control on a flood-dependent riparian forest. Ecol Appl 15:1019-1035

Lesica P, Miles S (1999) Russian olive invasion into cottonwood forests along a regulated river in northcentral Montana. Canadian Journal of Botany-Revue Canadienne De Botanique 77:1077-1083

Liu CR, Berry PM, Dawson TP, Pearson RG (2005) Selecting thresholds of occurrence in the prediction of species distributions. Ecography 28:385-393

Naiman RJ, Decamps H, Pollock M (1993) The role of Riparian corridors in maintaining regional biodiversity. Ecol Appl 3:209-212

NPS (2003) Data and Information: Data Clearinghouse. National Park Service

Phillips SJ (2008) Transferability, sample selection bias and background data in presence-only modelling: a response to Peterson et al. (2007). Ecography 31:272-278

Phillips SJ, Anderson RP, Schapire RE (2006) Maximum entropy modeling of species geographic distributions. Ecol Modell 190:231-259
Phillips SJ, Dudik M, Elith J, Graham CH, Lehmann A, Leathwick J, Ferrier S (2009) Sample selection bias and presence-only distribution models: implications for background and pseudo-absence data. Ecol Appl 19: 181-197

Quinn JF, Thorne J (2007) California invasive plant data

Reynolds LV, Cooper DJ (2010) Environmental tolerance of an invasive riparian tree and its potential for continued spread in the Southwestern US. J Veg Sci 1-11. doi:10.1111/ j.1654-1103.2010.01179.x

Richard SH, White P (2001) Horticulture as a pathway of invasive plant introductions in the United States. Bioscience 51:103-113

Richardson DM, Holmes PM, Esler KJ, Galatowitsch SM, Stromberg JC, Kirkman SP, Pysek P, Hobbs RJ (2007) Riparian vegetation: degradation, alien plant invasions, and restoration prospects. Divers Distrib 13:126-139

Sabo JL, Sponseller R, Dixon M, Gade K, Harms T, Heffernan J, Jani A, Katz G, Soykan C, Watts J, Welter A (2005) Riparian zones increase regional species richness by harboring different, not more, species. Ecology 86:56-62

Shafroth PB, Auble GT, Scott ML (1995) Germination and establishment of the native plains cottonwood (PopulusDeltoides Marshall Subsp Monilifera) and the exotic Russian-olive (Elaeagnus-Angustifolia L). Conserv Biol 9:1169-1175

Shafroth PB, Beauchamp VB, Briggs MK, Lair K, Scott ML, Sher AA (2008) Planning riparian restoration in the context of Tamarix control in western North America. Restor Ecol 16:97-112

Stohlgren TJ, Bull KA, Otsuki Y, Villa CA, Lee M (1998) Riparian zones as havens for exotic plant species in the central grasslands. Plant Ecol 138:113-125

Stohlgren TJ, Schell LD, Bull KA, Otsuki Y, Newman G, Bashkin M, Son Y, Binkley D, Chong GW, Kalkhan MA (1999) Exotic plant species invade hot spots of native plant diversity. Ecol Monogr 69:25-46

Strayer DL, Eviner VT, Jeschke JM, Pace ML (2006) Understanding the long-term effects of species invasions. Trends Ecol Evol 21:645

Swets JA (1988) Measuring the accuracy of diagnostic systems. Science 240:1285-1293

Thomas K, Guertin P (2007) Southwest non-native invasive plant database (SWEMP07). U.S. Geological Survey, Southwest Biological Science Center (USGS-SBSC)

USDA (2009) The PLANTS Database, National Plant Data Center, NRCS on

Utah BLM (2006) Utah noxious weeds. Bureau of Land Management

Vieira J (2003) Royal Gorge area weed mapping data. Bureau of Land Management

Wilson JRU, Richardson DM, Rouget M, Proches S, Amis MA, Henderson L, Thuiller W (2007) Residence time and potential range: crucial considerations in modelling plant invasions. Divers Distrib 13:11-22 